\title{
Qualitative Study on the Role of Men in Maternal Health in Resource-Limited Communities in Western Kenya
}

\section{Citation}

Brubaker, Kathryn Ann. 2017. Qualitative Study on the Role of Men in Maternal Health in Resource-Limited Communities in Western Kenya. Doctoral dissertation, Harvard Medical School.

\section{Permanent link}

http://nrs.harvard.edu/urn-3:HUL.InstRepos:40621352

\section{Terms of Use}

This article was downloaded from Harvard University's DASH repository, and is made available under the terms and conditions applicable to Other Posted Material, as set forth at http:// nrs.harvard.edu/urn-3:HUL.InstRepos:dash.current.terms-of-use\#LAA

\section{Share Your Story}

The Harvard community has made this article openly available. Please share how this access benefits you. Submit a story. 
Scholarly Report submitted in partial fulfillment of the MD Degree at Harvard Medical School

Student Name: Kathryn Brubaker, B.A.

Scholarly Report Title: Qualitative Study on the Role of Men in Maternal Health in ResourceLimited Communities in Western Kenya

\section{Mentor Name(s) and Affiliations:}

Roy Ahn, MPH, ScD, National Opinion Research Center, University of Chicago

Brett D. Nelson, MD, MPH, Departments of Pediatrics and Emergency Medicine, Massachusetts General Hospital

\section{Collaborators, with Affiliations:}

Brett D. Nelson, MD, MPH, Departments of Pediatrics and Emergency Medicine, Massachusetts General Hospital

Heather McPherson, Department of Emergency Medicine, Massachusetts General Hospital

Roy Ahn, MPH, ScD, National Opinion Research Center, University of Chicago

Monica Oguttu, Kisumu Medical Education Trust

Thomas Burke, MD, Departments of Pediatrics and Emergency Medicine, Massachusetts

General Hospital 
Title: Qualitative Study on the Role of Men in Maternal Health in Resource-Limited Communities in Western Kenya

Kathryn Brubaker, Brett D. Nelson, Heather McPherson, Roy Ahn, Monica Oguttu, Thomas F. Burke

Purpose: To better understand the beliefs of men and women in western Kenya regarding the appropriate role of men in maternal health and to identify barriers to greater involvement.

Methods: Between June 1 and July 31, 2014, a cross-sectional qualitative study enrolled lay men, lay women, and community health workers from Kisumu and Nyamira counties in western Kenya. Semi-structured focus group discussions were conducted and qualitative approaches were utilized to analyze the transcripts and identify common themes.

Results: In total, 134 individuals participated in 18 focus group discussions. Participants discussed the role of men and a general consensus was recorded that it was a man's duty to protect women during pregnancy. When discussing obstacles to male involvement, female participants highlighted gender dynamics and male participants raised financial limitations.

Conclusion: There was considerable discrepancy between how men described their roles and how they actually behaved, although educated men appeared to describe themselves as performing more supportive behaviors compared with male participants with less education. It is suggested that interventions aimed at increasing male involvement should incorporate existing culturally sanctioned roles men perform as a foundation upon which to build, rather than attempting to construct roles that oppose prevailing norms. 
I developed the idea for this study in conjunction with Dr. Roy Ahn and Dr. Thomas Burke. Their division was studying the implementation of the uterine balloon tamponade, a device that can be used by a variety of providers to treat postpartum hemorrhage. I was interested in developing a project that was complementary to their work but which examined social attitudes. The department partners with an indigenous NGO called KMET, the Kisumu Medical Education Trust. KMET had recently begun working on a project to better understand male attitudes towards abortion. Hoping to carry out an extension of their work, I developed the idea for this study on male attitudes and roles in pregnancy and childbirth.

In Kenya, the director of KMET is Monica Oguttu. She helped me to further refine my objectives and connected me with a community health worker, Caleb Owelo, who was interested in helping with the project. Dr. Ahn helped me to refine my interview guide and to identify the different kinds of communities that I would want to include in my study. Mr. Owelo recruited participants for the focus groups in each of the communities that we identified. Mr. Owelo and myself facilitated all of the focus groups and he provided interpretation when needed.

I transcribed all of the recorded focus groups and carried out the first round of analysis and coding using NVivo software. I identified themes and developed the code structure. Another researcher coded the focus groups independently and we resolved any discrepancies in our analysis through discussion.

I wrote the first draft of the paper, including a short literature review on other studies that examined male attitudes towards pregnancy and childbirth. Dr. Brett Nelson was essential in developing the appropriate style and structure of the paper, given the journal to which we were planning on submitting the paper. Dr. Ahn and Dr. Burke also made revisions to the draft. Dr. Nelson managed all contact with the journal. He and myself developed the responses to feedback and made revisions after our initial submission. 


\section{Citation}

Brubaker K, Nelson BD, McPherson H, Ahn R, Oguttu M, Burke TF. Qualitative study of the role of men in maternal health in resource-limited communities in western Kenya. International Journal of Gynecology \& Obstetrics. 2016 Dec; 135(3):245-9.

\section{Link}

http://onlinelibrary.wiley.com/wol1/doi/10.1016/j.ijgo.2016.06.015/full 
CLINICAL ARTICLE

\title{
Qualitative study of the role of men in maternal health in resource-limited communities in western Kenya
}

\author{
Kathryn Brubaker a,b, Brett D. Nelson ${ }^{\mathrm{a}, \mathrm{b}, *}$, Heather McPherson ${ }^{\mathrm{a}}$, Roy Ahn ${ }^{\mathrm{a}}$, \\ Monica Oguttu ${ }^{\mathrm{c}}$, Thomas F. Burke ${ }^{\mathrm{a}, \mathrm{b}, \mathrm{d}}$ \\ ${ }^{a}$ Division of Global Health and Human Rights, Department of Emergency Medicine, Massachusetts General Hospital, Boston, MA, USA \\ ${ }^{\text {b } H a r v a r d ~ M e d i c a l ~ S c h o o l, ~ B o s t o n, ~ M A, ~ U S A ~}$ \\ c Kisumu Medical and Education Trust, Kisumu, Kenya \\ ${ }^{d}$ Harvard T.H. Chan School of Public Health, Boston, MA, USA
}

\section{A R T I C L E I N F O}

\section{Article history:}

Received 15 March 2016

Received in revised form 29 May 2016

Accepted 10 August 2016

\section{Keywords:}

Community health workers

Developing countries

Male involvement

Male role

Maternal health

Maternal mortality

Perceptions

Reproductive health

\begin{abstract}
A B S T R A C T
Objective: To better understand the beliefs of men and women in western Kenya regarding the appropriate role of men in maternal health and to identify barriers to greater involvement. Methods: Between June 1 and July 31, 2014, a cross-sectional qualitative study enrolled lay men, lay women, and community health workers from Kisumu and Nyamira counties in western Kenya. Semi-structured focus group discussions were conducted and qualitative approaches were utilized to analyze the transcripts and identify common themes. Results: In total, 134 individuals participated in 18 focus group discussions. Participants discussed the role of men and a general consensus was recorded that it was a man's duty to protect women during pregnancy. When discussing obstacles to male involvement, female participants highlighted gender dynamics and male participants raised financial limitations. Conclusion: There was considerable discrepancy between how men described their roles and how they actually behaved, although educated men appeared to describe themselves as performing more supportive behaviors compared with male participants with less education. It is suggested that interventions aimed at increasing male involvement should incorporate the existing culturally sanctioned roles men perform as a foundation upon which to build, rather than attempting to construct roles that oppose prevailing norms.

(c) 2016 International Federation of Gynecology and Obstetrics. Published by Elsevier Ireland Ltd. All rights reserved.
\end{abstract}

\section{Introduction}

Maternal mortality has decreased worldwide by more than $45 \%$ over the past 20 years [1]. Despite this enormous shift, some low- and middle-income countries have struggled to improve maternal mortality ratios (MMRs). The MMR in Kenya remains unacceptably high at 362 per 100000 live deliveries and some regions, such as Mandera County (approximately 3500 per 100000 live deliveries), have MMRs that are among the highest in the world [2].

Since the International Conference on Population and Development [3] and the Fourth World Conference on Women [4], increased male partner involvement has been emphasized as a strategy to improve reproductive and maternal health outcomes. Greater male involvement during pregnancies has been associated with increases in family birth plans [5], increases in women undergoing delivery with skilled birth attendants [6], increases in first-trimester prenatal care visits [7], and reductions in low birth-weight neonates [8].

* Corresponding author at: Division of Global Health and Human Rights, Department of Emergency Medicine, Massachusetts General Hospital, 125 Nashua St. Suite 910, Boston, MA 02114, USA. Tel.: + 1617643 4294; fax: + 16176438772.

E-mail address: brett.d.nelson@gmail.com (B.D. Nelson).
Little is known about the views of both men and women regarding male roles during pregnancy and childbirth, as well as any barriers to fulfilling those roles. To gain increased understanding regarding perceptions of male roles in reproductive health in Kenya, focus group discussions were conducted with men whose partners had given birth, women who had given birth, and community health workers (CHWs). The aim of the present study was to better understand the current role of men in maternal health and how their involvement might be increased.

\section{Materials and methods}

A cross-sectional qualitative study enrolled women, men, and CHWs from the city of Kisumu, Kenya, the seven surrounding sub-counties, and Nyamira County between June 1 and July 31, 2014. Participants were recruited by an experienced CHW employed at the Kisumu Medical and Education Trust using purposeful sampling to ensure that the focus groups included women who delivered at facilities and women who underwent delivery at home. Recruitment continued until thematic saturation was reached. The study received ethical approval from the institutional review board of Partners HealthCare (Boston, MA, USA) and the ethical review board of Maseno University 
School of Medicine (Maseno, Kenya). Verbal informed consent was obtained from participants prior to beginning the focus group discussions.

A semi-structured instrument was used to guide focus group discussions of 45-90 minutes in length. Focus groups ranged in size from three to 15 participants, with the majority of groups having between six and nine participants. The topics included participants' delivery experiences and preparations, individual and community expectations surrounding male roles, and obstacles to male involvement. One of the researchers (K.B.) facilitated the conversations with the assistance of a local Kenyan translator who was also a CHW. All discussion members were encouraged to participate. Audio recordings of the focus group discussions were subsequently transcribed. Participants were compensated 200 Kenyan Shillings (approximately US\$ 2.25) for their time.

A hybrid approach was employed whereby two researchers (K.B. and H.M.) independently analyzed and coded the interviews via a previously described "integrated approach" including "a combination of an inductive (ground-up) approach to the development of codes with a deductive organizing framework for code types (start list)" [9]. The analyses began by a thorough reading of transcripts before developing the code structure. The data were reviewed line by line and codes were assigned to reflect emerging concepts. Coding reliability was established between the two coders; line-by-line coding was performed independently before the researchers compared results and resolved any discrepancies through discussion. Once the code structure was finalized and the themes identified, NVivo 9 (QSR International, Victoria, Australia) qualitative research software was used to organize and analyze the data.

\section{Results}

In total, 18 focus group discussions included 134 participants (Tables 1-3). The focus groups including CHWs contained both male and female participants; all but one of the remaining focus groups were segregated by gender. The focus groups ranged in size from three to 15 participants, with the majority having between seven and 12 participants. Qualitative analyses of the discussion transcripts yielded a number of recurring major topics and themes that are outlined with examples in Table 4.

Delivery and childbirth were seen as the domain of women, with all of the male participants reporting that there was an important role for the male as the head of the family. At every focus group discussion it was asserted that in Kenya, the husband has a duty to provide for the family. Actions suggested in the focus groups as male responsibilities included the provision of food and other material goods, as well as physical and emotional support during the pregnancy.

Several male participants described a responsibility among men to provide their wives with sufficient nourishment for a healthy pregnancy

Table 1

Focus group participants. ${ }^{\text {a }}$

\begin{tabular}{ll}
\hline Focus group features & Value \\
\hline Focus group discussions & 18 \\
Discussions in Kisumu County & 15 \\
Discussions in Nyamira County & 3 \\
Discussions including lay women & 8 \\
Discussions including lay men & 4 \\
Discussions including CHWs only & 2 \\
Discussions including CHWs and lay men & 1 \\
Discussions including CHWs and lay women & 2 \\
Discussions including mixed-gender community members & 1 \\
Focus group participants & 134 \\
Lay women & 70 \\
Age, y & $24.9(15-40)$ \\
Lay men & 40 \\
Age, y & $27.5(18-50)$ \\
CHWs & 24
\end{tabular}

Abbreviation: CHW, community health workers.

${ }^{a}$ Values are given as number or mean (range).
Table 2

Education level of lay focus group participants. ${ }^{\text {a }}$

\begin{tabular}{lll}
\hline Education level & Male participants $(\mathrm{n}=40)$ & Female participants $(\mathrm{n}=70)$ \\
\hline No formal schooling & 0 & $1(1)$ \\
Some primary & $1(3)$ & $13(19)$ \\
Completed primary & $11(28)$ & $30(439)$ \\
Some secondary & $3(8)$ & $11(16)$ \\
Completed secondary & $16(40)$ & $7(10)$ \\
University & $5(13)$ & $2(3)$ \\
Data missing & $4(10)$ & $6(9)$ \\
\hline
\end{tabular}

${ }^{a}$ Values are given as number (percentage).

and, consequently, healthy children. Food was the most frequently discussed provision; however, some male participants spoke of commodities needed at hospitals and items for the neonate following delivery. Alongside the material provisions and monetary means identified, one of the most important male roles described was to secure transportation in advance of the onset of labor.

A majority of female participants indicated that men should offer material assistance during pregnancy. Many also described saving their own money and saving some of the money that their partners had given them for other uses.

This topic was described by a female participant, "I can also say that nowadays women are involved in some income-generating activities so they are not depending on their husband that much. They are also earning their money."

In addition to material support, male participants in every focus group discussed the importance of supporting their wives with household tasks and chores that were increasingly challenging during pregnancy. To avoid the potential negative consequences of heavy lifting and hard physical labor, male participants reported that they offered assistance so that their partners could avoid increased physical stress.

The most common response from female participants, when discussing the role of men during pregnancy, was the importance of men working around the home and assisting with manual labor.

A theme described several times was that men needed to not only protect their wives from physical factors that could endanger the pregnancy, but also assist in protection from emotional stressors, such as domestic disputes. Some male participants suggested that women were at times unreasonable during pregnancy but that men should try to get along and avoid adding stress. A few male participants described the importance of behaving in a loving and supportive manner during pregnancy.

The focus on emotional support in some male focus group discussions was not mirrored in the discussions among female participants regarding important roles for men during pregnancy. Compared with the six male participants who explicitly mentioned the need to love and be kind during pregnancy, only one woman specifically mentioned love. The female participants who discussed emotional support from their partners described the importance of not being beaten but instead, feeling supported.

After discussing the role that men should play during pregnancy, participants identified factors that prevented them from doing so.

When asked about barriers to male involvement during pregnancy, male participants in every focus group spontaneously indicated that poverty limited their ability to support their partners. A point of

Table 3

Family history of lay focus group participants. ${ }^{\mathrm{a}}$

\begin{tabular}{lll}
\hline No. of children & Male participants $(\mathrm{n}=40)$ & Female participants $(\mathrm{n}=70)$ \\
\hline 0 or expecting & $13(33)$ & 0 \\
$1-3$ & $18(45)$ & $48(69)$ \\
$4-6$ & $3(8)$ & $19(27)$ \\
$\geq 7$ & $1(3)$ & $3(4)$ \\
Data missing & $5(13)$ & 0 \\
\hline a Values are given as number (percentage)
\end{tabular}

${ }^{a}$ Values are given as number (percentage). 
Table 4

Key topics and themes identified in focus group discussions.

\begin{tabular}{|c|c|c|}
\hline Themes & Illustrative quotes & Focus group participant \\
\hline \multicolumn{3}{|c|}{ Topic 1 : Male roles in pregnancy and childbirth } \\
\hline \multicolumn{3}{|c|}{ Provider } \\
\hline \multirow[t]{4}{*}{ Opinions of male participants } & $\begin{array}{l}\text { "What [pregnant women] really want most from the men is for the men to take care of them. To eat } \\
\text { well while they are pregnant so they can deliver easily and so they can be strong after birth." }\end{array}$ & Lay male in Nyando \\
\hline & $\begin{array}{l}\text { "He should take care of her in the sense of diet. He should give her the necessary foods which will } \\
\text { make the child grow healthy." }\end{array}$ & Male CHW in Central Kisumu \\
\hline & $\begin{array}{l}\text { "The preparation that you can do is maybe when the wife has gotten pregnant, [the husband] can } \\
\text { prepare some extra cash and put it aside for transport on the way to hospital when the labor comes, } \\
\text { and maybe for medication maybe if something goes wrong, and for food." }\end{array}$ & Lay male in Nyando \\
\hline & "I planned and talked to my cousin who had a car and who was willing to take my wife to the hospital." & Lay male in Nyamira \\
\hline \multirow[t]{2}{*}{ Opinions of female participants } & "I stashed money from food money so that I could buy things for the baby." & Lay female in Kisumu East \\
\hline & "When my husband gave me money to use in the house I saved some money for my baby." & Lay female in Kisumu East \\
\hline \multirow[t]{2}{*}{ Physical protection } & $\begin{array}{l}\text { "The husband should also relieve the wife from some hard activities that might interfere with the } \\
\text { child... I'm talking about hard jobs. Maybe digging because this can maybe injure the child." }\end{array}$ & $\begin{array}{l}\text { Lay male youth in Central } \\
\text { Kisumu }\end{array}$ \\
\hline & $\begin{array}{l}\text { "Like food, like water, you can fetch for her or maybe get somebody to get you some of the basic } \\
\text { commodities that are needed within the household because [the husband] is acting as the helper } \\
\text { of the woman." }\end{array}$ & Lay male in Kisumu West \\
\hline \multirow[t]{5}{*}{ Emotional protection } & $\begin{array}{l}\text { "He's saying that when a woman is pregnant, as a man, you have to avoid giving her stress by } \\
\text { involving her in domestic violence or quarrels or maybe exchanging words. Because it gives a } \\
\text { woman who is pregnant a lot of stress and it can affect the baby." }\end{array}$ & Lay male in Nyando \\
\hline & "The other things is also, you as the husband, you don't just give her transport and you sit there. & Male CHW in Central Kisumu \\
\hline & Let the wife feel that she is appreciated because this is not a prostitute. This is somebody who was & \\
\hline & here at home, you were together, you prepared yourself psychologically to actually have the child. & \\
\hline & So preparing her psychologically, having her feel that she is appreciated, very, very much important." & \\
\hline \multicolumn{3}{|c|}{ Topic 2: Obstacles to increased male involvement } \\
\hline \multirow[t]{2}{*}{ Financial/work obligations } & $\begin{array}{l}\text { "Some [husbands] will be positive, but the majority will tell you due to economic hardship they may } \\
\text { not be able to do what you are telling them. The advice, the health talks you are giving them is good, } \\
\text { but the economy is so hard that one can go without food in a day. So telling him the other thing } \\
\text { [planning and saving money for childbirth] is like a dream. So that is one of the challenges } \\
\text { I am finding." }\end{array}$ & Male CHW in Central Kisumu \\
\hline & $\begin{array}{l}\text { "So maybe he's working at night somewhere and coming back in the morning and found that the } \\
\text { pregnant woman got delivered. Maybe he wouldn't know where the woman delivered but maybe } \\
\text { at the traditional birth attendant's place. Or even the hospital, but he can't know." }\end{array}$ & Lay male in Kisumu East \\
\hline \multirow[t]{5}{*}{$\begin{array}{l}\text { Cultural expectations around } \\
\text { gender }\end{array}$} & $\begin{array}{l}\text { "Men assume that after you get married, all of his duty and his work is to search [for food]... If the } \\
\text { woman is pregnant, the man assumes that all of the [household] duties are just for the woman. } \\
\text { His job is to go and search for the food." }\end{array}$ & $\begin{array}{l}\text { Lay male youth in Central } \\
\text { Kisumu }\end{array}$ \\
\hline & "They fear that this is a woman's job, a woman's duty." & Lay female in Kisumu East \\
\hline & $\begin{array}{l}\text { "When you accompany your wife to the clinic, what other men would say is that your wife has } \\
\text { overpowered you. Your wife has more power than you, so whatever your wife tells you is what } \\
\text { you do. So it is like your wife has belittled you, and then they would start talking badly about you." }\end{array}$ & Lay male in Nyando \\
\hline & $\begin{array}{l}\text { "In our culture, men are not supposed to discuss very many things about giving birth or even sitting } \\
\text { where a woman is giving birth. So, in this cultural context, you go into a house, and you find the } \\
\text { husband there. The woman can introduce you, and after that, the man says, 'Now, I leave you. } \\
\text { You discuss with the momma."' }\end{array}$ & Male CHW in Nyamira \\
\hline & $\begin{array}{l}\text { "That tie that was holding us to old traditions is getting weaker and we are adapting to modern } \\
\text { things. We see and feel that you [the man] are part of this pregnancy and you should also raise } \\
\text { your child together... The call of responsibility is getting among the men these days" }\end{array}$ & Lay male in Central Kisumu \\
\hline Polygamy & $\begin{array}{l}\text { "Our culture also allows men to have many women, so the man may ask the woman, "If I accompany } \\
\text { you today, then the following one would also want to be accompanied. Now, how much time will } \\
\text { I take accompanying you every night to the hospital?" }\end{array}$ & Lay female in Nyamira \\
\hline Men and labor & $\begin{array}{l}\text { "In Luo culture, if the man sees the wife giving birth with his own eyes, he makes the lady not give } \\
\text { birth anymore. That is the first and the last chance. The lady will not give birth anymore because of } \\
\text { the man, because the man watched her give birth." }\end{array}$ & Lay male in Nyando \\
\hline Hospital policies & $\begin{array}{l}\text { "When your wife is in labor and you take her to the hospital, you will always be chased away. } \\
\text { You won't enter with your wife the maternity room." }\end{array}$ & Lay male in Central Kisumu \\
\hline
\end{tabular}

Abbreviation: CHW, community health worker.

discussion was that if a man attended prenatal clinic visits with his partner, these were times that he was not working, making money, or finding food. The provider role was discussed as a limitation on the time that could be spent with partners in healthcare settings.

A male participant from West Kisumu stated, "You [as husband] are the role model in the house, you are the breadwinner. You can't come and sit with your wife here in the line [at the clinic]. And yet your wife will come back from the hospital, they want to eat with the entire family. So how will you come and sit down here with her? It's very hard."

Men reported traveling long distances and working far from the homestead, and that this made it difficult for them to be present at the time of birth.
When asked about why their husbands had not been involved in helping them reach healthcare facilities or a traditional birth attendant, several female participants replied simply that they had been, "away." Only one focus group with female participants explicitly discussed income as limiting their partner's ability to participate.

Both male and female focus group participants reported traditional expectations of gender roles as preventing men from offering care and support to their partners. Money and gender roles were discussed with similar frequency among male participants; however, the impact of traditional gender roles as barriers to male involvement dominated discussions in female focus groups. By way of example, although many focus group members described help with household chores as an important role for men during pregnancy, this preferred behavior was 
not in keeping with descriptions of actual day-to-day life. Despite both male and female participants describing this as being beneficial during pregnancy, traditional gender roles of men not being helpful around the house were prevalent.

These gendered expectations impacted not only the roles that men played inside the home, but also the extent to which they were involved in their partner's pregnancy outside of the home. Several male participants mentioned the importance of reminding their partners of prenatal clinic appointments; however, they also reported that they would receive social censure for accompanying their wives to prenatal clinics.

Several male CHWs participated in the focus group discussions; CHWs described experiences involving male partners as being fraught with barriers arising from traditional gender roles. A male CHW who participated in the focus groups described such an experience, "In our culture, men are not supposed to discuss very many things about giving birth or even sitting where a woman is giving birth. So, in this cultural context, you go into a house, and you find the husband there. The woman can introduce you, and after that, the man says, "Now, I leave you. You discuss with the momma."'

Although it was not discussed as widely in the focus group discussions as poverty and gender norms, polygamy was raised as a pertinent factor. Several participants indicated that, although the practice of polygamy was decreasing in frequency, being involved in a polygamous partnership reduced the likelihood of men being closely involved in pregnancy and delivery for any one partner owing to a need to distribute their time. Both male and female participants reported that fellow wives could support one another within polygamous relationships.

A traditional belief that if a man was present in the delivery room, the process of labor would stall was described by both male and female participants. This particular idea surfaced independently in five of the focus groups when participants were asked about traditional or cultural beliefs that limited male involvement in maternal health care. Finally, a small number of male participants described varying experiences about the roles they were permitted to assume at different facilities during labor and delivery. Some reported being able to stay with their partners and others reported being forced to leave.

\section{Discussion}

In the present study, male and female participants appeared to be in agreement that men should provide food and money for their partners, and that they should help with hard physical housework. However, female participants also emphasized the extent to which they relied on their own resources and male participants were more likely to discuss providing emotional support. All participants described poverty and traditional gender roles as important barriers to increased male involvement during pregnancy and delivery.

The perception of husbands as the "providers" of basic goods-food and clothes-has been reported previously [10,11], and emerged in the present study. Each focus group unanimously noted that the husband was responsible for providing his wife with food. Additionally, when facility-based delivery was understood by male participants to be a vital priority they would buy-in, in-keeping with their role as "provider". However, for many female participants and families represented in the focus groups, and as reported elsewhere [12], facility delivery was frequently viewed as desirable but not necessary. A recurring theme was a discrepancy between how men viewed their roles as provider and the limited extent to which women ultimately relied upon them. This was pronounced when discussing financial resources, with many male participants reporting that it was their job to provide financially; however, many female participants reported saving money on their own for fear of no other support.

The traditional and near-universal understanding of men as providers is particularly challenging in low-income settings like Kenya where families and communities often subsist on a day-to-day basis.
The idea of men attending prenatal care visits could be particularly challenging because it conflicts not only with entrenched gender norms, but also with the responsibility that men feel to provide food and money for their family-time spent at a clinic is time spent not working. While prenatal clinic visits could be a valuable opportunity to provide husbands with education, pursuing this agenda in many circumstances could ultimately be counter-productive and fail owing to significant conflicts with deeply entrenched indigenous factors.

It has been reported elsewhere that increased male involvement in reproductive health is linked closely with education levels $[5,13,14]$. In the present study, male participants who were more involved in caring for their wives generally considered themselves educated and progressive, as opposed to effeminate or weak. For these participants, they felt that the ability to plan and provide for their wives' needs, particularly regarding transportation and facility-based delivery, was not only a sign of their intelligence and education, but also of their wealth. By framing their involvement in this way, these participants were able to defend their involvement in their wives' care as constituting fulfillment of a man's culturally appropriate role of provider.

An unfortunate unintended consequence of a program to incentivize male involvement in pregnancy was reported recently in Malawi [15]; it described chiefs discouraging healthcare providers from caring for women who presented at clinics alone. Following on from this and examples in Kenya of some neighborhood clinics prioritizing care for couples head of women who attended alone [11], the Kenyan government and maternal health stakeholders need to be vigilant to ensure that attempts to involve men do not diminish women.

There were several important limitations to the present study. First, the perceptions reported could not necessarily be generalizable beyond the participants; however, the number and diversity of focus group participants, combined with thematic saturation being reached in the study, strongly suggest that the findings reflect the larger community. Second, it is important to consider the possibility of social desirability bias; as the focus on improving maternal health has grown, the message that deliveries should occur in a hospital has spread widely. Consequently, participants could have been reluctant to disclose opinions or behaviors opposed to this message. Attempts were made to minimize this bias by emphasizing the confidentiality of the discussions and a desire to hear all points of view.

While increased male involvement in maternal health careparticularly in ensuring prenatal care and facility-based delivery-is seen as important to reducing maternal mortality in low- and middleincome countries, the present study found considerable discrepancies between how men described their role and how women described their experiences. Men who violate gendered social norms through increased involvement with their partners' care often face censure; their need to defend their position as progressive and educated demonstrates how deeply such norms are ingrained. It is recommended that interventions aimed at increasing male involvement carefully consider prevailing gender norms and work with communities to create programs that educate and prepare men, but that this is performed in a way that does not directly contradict prevailing norms. Interventions that support and expand culturally sanctioned ways that men are already involved in the care of their partners are more likely to succeed than those that attempt to define new roles contradicting those already accepted.

\section{Acknowledgments}

The present study was funded by Ujenzi Charitable Trust and Harvard Medical School. The authors would like to thank Caleb Okelo for his critical help with study recruitment and translation.

\section{Conflict of Interest}

The authors have no conflicts of interest to report. 


\section{References}

[1] World Health Organization. Trends in Maternal Mortality: 1990 to 2013 Estimates by WHO, UNICEF, UNFPA, The World Bank and the United Nations Population Division. http://www.who.int/reproductivehealth/publications/monitoring/maternalmortality-2013/en/. Published 2014. Accessed August 9, 2016.

[2] Kenya National Bureau of Statistics. Kenya Demographic and Health Survey. https:// dhsprogram.com/pubs/pdf/FR308/FR308.pdf. Published 2015. Accessed August 9, 2016.

[3] United Nations Population Fund. Report of the International Conference on Population and Development. Cairo 5-13 Sept 1994. https://www.unfpa.org/sites/default/files/ event-pdf/icpd_eng 2.pdf. Published 1995.

[4] United Nations. Report of the Fourth World Conference on Women. Beijing 4-15 September 1995. http://www.un.org/womenwatch/daw/beijing/pdf/Beijing\% 20full\%20report\%20E.pdf. Published 1996.

[5] Kakaire O, Kaye DK, Osinde MO. Male involvement in birth preparedness and complication readiness for emergency obstetric referrals in rural Uganda. Reprod Health 2011;8:12.

[6] Mageni JN, Mwagni A, Mbugua S, Mukthar V. Male Involvement in Maternal Health Care as a Determinant of Utilization of Skilled Birth Attendants in Kenya. http://www.dhsprogram.com/pubs/pdf/WP93/WP93.pdf. Published 2013. Accessed August 9, 2016.

[7] Martin LT, McNamara MJ, Milot AS, Halle T, Hair EC. The effects of father involvement during pregnancy on receipt of prenatal care and maternal smoking. Matern Child Health J 2007;11(6):595-602.
[8] Alio AP, Salihu HM, Kornosky JL, Richman AM, Marty PJ. Feto-infant health and survival: does paternal involvement matter? Matern Child Health J 2010;14(6):931-7.

[9] Bradley EH, Curry LA, Devers KJ. Qualitative data analysis for health services research: developing taxonomy, themes, and theory. Health Serv Res 2007;42(4): 1758-72.

[10] Singh D, Lample M, Earnest J. The involvement of men in maternal health care: cross-sectional, pilot case studies from Maligita and Kibibi, Uganda. Reprod Health 2014;11:68.

[11] Kwambai TK, Dellicour S, Desai M, Ameh CA, Person B, Achieng F, et al. Perspectives of men on antenatal and delivery care service utilisation in rural western Kenya: a qualitative study. BMC Pregnancy Childbirth 2013;13:134.

[12] Kitui J, Lewis S, Davey G. Factors influencing place of delivery for women in Kenya: an analysis of the Kenya demographic and health survey, 2008/2009. BMC Pregnancy Childbirth 2013;13:40.

[13] Byamugisha R, Tumwine JK, Semiyaga N, Tylleskär T. Determinants of male involvement in the prevention of mother-to-child transmission of HIV programme in Eastern Uganda: a cross-sectional survey. Reprod Health 2010;7:12.

[14] Tweheyo R, Konde-Lule J, Tumwesigye NM, Sekandi JN. Male partner attendance of skilled antenatal care in peri-urban Gulu district, Northern Uganda. BMC Pregnancy Childbirth 2010;10:53.

[15] Kululanga LI, Sundby J, Malata A, Chirwa E. Striving to promote male involvement in maternal health care in rural and urban settings in Malawi - a qualitative study. Reprod Health $2011 ; 8: 36$. 